\title{
Evaluation of goodness of fit of semiparametric and para- metric models in analysis of factors associated with length of stay in neonatal intensive care unit
}

Fatemeh Kheiry, MSc ${ }^{1}$, Sadegh Kargarian-Marvasti, MSc ${ }^{2}$, Sima Afrashteh, MSc ${ }^{3}$, Abolfazl Mohammadbeigi, Phd ${ }^{4}$, Nima Daneshi ,MSc ${ }^{5}$, Salma Naderi, MD ${ }^{6}$, Seyed Hossein Saadat, MD $^{7}$

${ }^{1}$ Student Research Committee, School of Nursing and Midwifery, Shiraz University of Medical Sciences, Shiraz, Iran; ${ }^{2}$ Department of Epidemiology, Isfahan University of Medical Sciences, Isfahan, Iran; ${ }^{3}$ Department of Public Health, Faculty of Health, Bushehr University of Medical Sciences, Bushehr, Iran; ${ }^{4}$ Department of Epidemiology and Biostatistics, Faculty of Health, Qom University of Medical Sciences, Qom, Iran; ${ }^{5}$ Behbahan Faculty of Medical Sciences, Behbahan, Iran; ${ }^{6}$ Department of Pediatrics, Faculty of Medicine, Clinical Research Development Centre of Children Hospital, Hormozgan University of Medical Sciences, Bandar Abbas, Iran; ${ }^{7}$ Faculty of Medicine, Clinical Research Development Center of Children's Hospital, Hormozgan University of Medical Sciences, Bandar Abbas, Iran

Background: Length of stay is a significant indicator of care effectiveness and hospital performance. Owing to the limited number of healthcare centers and facilities, it is important to optimize length of stay and associated factors.

Purpose: The present study aimed to investigate factors associated with neonatal length of stay in the neonatal intensive care unit (NICU) using parametric and semiparametric models and compare model fitness according to Akaike information criterion (AIC) between 2016 and 2018.

Methods: This retrospective cohort study reviewed 600 medical records of infants admitted to the NICU of Bandar Abbas Hospital. Samples were identified using census sampling. Factors associated with NICU length of stay were investigated based on semiparametric Cox model and 4 parametric models including Weibull, exponential, log-logistic, and log-normal to determine the best fitted model. The data analysis was conducted using R software. The significance level was set at 0.05 . Results: The study findings suggest that breastfeeding, phototherapy, acute renal failure, presence of mechanical ventilation, and availability of central venous catheter were commonly identified as factors associated with NICU length of stay in all 5 models $(P<0.05)$. Parametric models showed better fitness than the Cox model in this study.

Conclusion: Breastfeeding and availability of central venous catheter had protective effects against length of stay, whereas phototherapy, acute renal failure, and mechanical ventilation increased length of stay in NICU. Therefore, the identification of factors associated with NICU length of stay can help establish effective interventions aimed at decreasing the length of stay among infants.

Key words: Semiparametric, Parametric models, Neonatal intensive care units, Length of stay, Iran

\section{Key message}

Question: Hospitalization in neonatal intensive care unit (NICU) is associated with life-threatening hazards. What factors associated with neonatal length of stay (LOS) in the NICU? Finding: Breastfeeding, phototherapy, acute renal failure (ARF), mechanical ventilation, and central venous catheter (CVC) access were identified as factors associated with NICU length of stay.

Meaning: Protective effects of breastfeeding and CVC access, whereas increase effects of phototherapy, ARF, and mechanical ventilation in LOS can be supporting evidence to establish effective interventions to reduce length of NICU stay.

\section{Introduction}

Identification of factors associated with neonatal length of stay (LOS) has become increasingly important, as elevated survival rate of premature infants is linked with prolonged hospitalization. Besides, it is necessary to estimate neonatal LOS to facilitate physician-parent communication regarding the predicted lifespan of the infant. ${ }^{1,2)}$

Hospitalization in neonatal intensive care unit (NICU) is associated with many life-threatening hazards and risks for the infant. A number of previous studies ${ }^{3,4)}$ have shown that $58 \%$ of infants with prolonged NICU stay were found dead or with severe disabilities after 1-year follow-up. Thus, identification of factors associated with NICU LOS may contribute to improve provided healthcare services and reduce neonatal LOS, as well as healthcare costs. ${ }^{5,6}$

Many studies have been carried out to determine causes of variability in survival distribution amongst different subgroups in heterogeneous populations. Comparison of parametric and semiparametric methods is a common technique to study predictors of survival distribution. There are 2 types of regres-

Corresponding author: Sima Afrashteh, MSc. Department of Public Health, Faculty of Health, Bushehr University of Medical Sciences, Bushehr, Iran 凶E-mail: sima.afrashte3@gmail.com, https://orcid.org/0000-0002-4276-2084

Received: 9 May, 2019, Revised: 17 January, 2020, Accepted: 31 January, 2020

This is an open-access article distributed under the terms of the Creative Commons Attribution Non-Commercial License (http://creativecommons.org/licenses/bync/4.0/) which permits unrestricted non-commercial use, distribution, and reproduction in any medium, provided the original work is properly cited.

Copyright (c) 2020 by The Korean Pediatric Society 


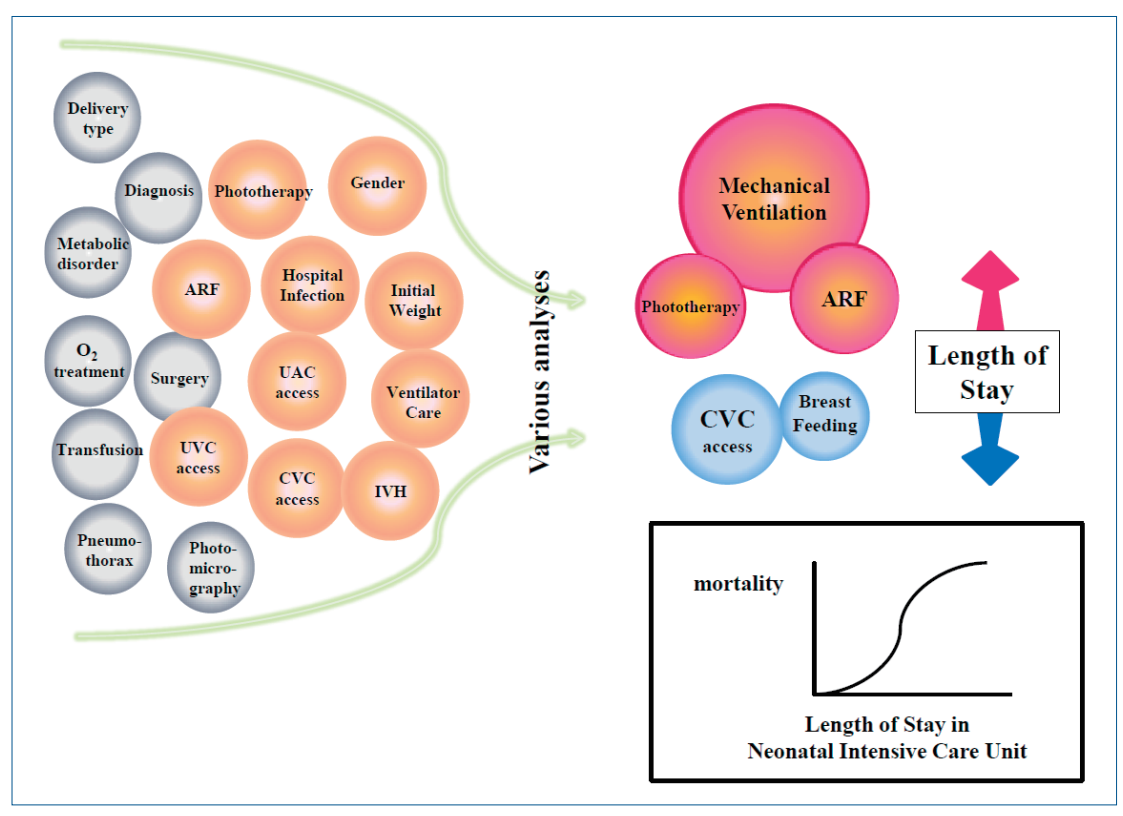

Graphical abstract. Factors associated with length of stay in neonatal intensive care unit. ARF, acute renal failure; UVC, umbilical venous catheter; UAC, umbilical arterial catheter; CVC, central venous catheter; IVH, intraventricular hemorrhage.

sion models for survival data: Cox proportional hazard model as a semiparametric method ${ }^{7}$ and accelerated failure time models such as Weibull, exponential, log-logistic, log-normal as parametric methods. Cox proportional hazard model is the most common method for modeling factors associated with survival. ${ }^{8,9)}$ As an advantage, no particular form of probability distribution is assumed for the survival times in Cox model. However, there is an important and basic assumption in this model called proportional hazards, assumes that the hazard functions for 2 different levels of a covariate are proportional for all independent variables in the final model. ${ }^{10-13)}$ As such, the hazard ratio (HR) for a person, is a constant value for another person at a certain time. ${ }^{14)}$ If this assumption is met, interpretation of the obtained model will be easier than the parametric models, whereas if parametric model assumptions are met, the Cox model can be the best fitness and more efficiently estimated. ${ }^{15)}$

Therefore, identification of risk factors for neonatal LOS in a clinical setting is very important, as it contributes to clinical diagnostic reasoning and supports clinical decisions. Furthermore, knowledge about risk factors associated with NICU LOS may help to develop strategies and interventions aimed at reducing mortality, neonatal LOS, and subsequently reducing related costs and complications. Therefore, the present study was carried out to evaluate factors associated with neonatal LOS in NICU using parametric and semiparametric models, and compare model fitness based on Akaike information criterion (AIC). The results of this study can be effectively used to reduce NICU LOS and consecutively reduce adverse effects and complications related to prolonged NICU stay.

\section{Methods}

This retrospective cohort study reviewed a total of 603 medical records of all NICU admitted newborns. First, a total of 600 infants admitted to NICU of Pediatric Department of Bandar Abbas Hospital with LOS longer than 24 hours were selected as target population. The required data on sex (male or female), type of delivery (normal or cesarean section), birth weight, type of feeding (breastfeeding, formula feeding), type of admission (emergency ward, other sections, other hospitals), nosocomial infection, antibiotic consumption during hospitalization, use of phototherapy, genetic disorders, metabolic disorders, acute renal failure, pneumothorax, use of mechanical ventilation, oxygen therapy, availability of umbilical arterial and venous catheters, availability of central venous catheter, intraventricular hemorrhage (IVH), blood product transfusion during the admission, and surgery during admission were collected by reviewing medical records of the patients.

The desired incident or failure in this study was death of infant admitted to NICU. Infants who were discharged by the physician's order or with the written consent of the parents at the end of the study were considered as censored cases.

Factor associated with LOS in NICU were evaluated using univariate $(P<0.20)$, and multivariate $(P<0.05)$ analyses based on semiparametric Cox model and 4 parametric models including Weibull, exponential, log-logistic and log-normal to determine the best fitted model. Data analysis was conducted using $\mathrm{R}$ ver. 3.2.3 (R Foundation for Statistical Computing, Vienna, Austria), with significance level at 0.05 .

This study was approved by the Ethics Committee (grant number: IR HUMS.REC.1397.07.02) of Bandar Abbas University of Medical Sciences. 


\section{Evaluation criterion}

The AIC proposed by Akaike ${ }^{16,17)}$ was used to evaluate and compare candidate models in this study. AIC is a criterion for the fitness of statistical models and shows which model is more suitable for fitting data. The AIC is calculated by the following equation: $\mathrm{AIC}=-2 \times \log$ (likelihood) $+2 \times(\mathrm{a}+\mathrm{c})$. Where, $\mathrm{a}$ is the number of parameters in the model, and $\mathrm{c}$ is a constant coefficient which is applied depending on the type of model. as such, for exponential model, the c equals 1 , while for Weibull, $\log$-logistic and log-normal models, the value of $\mathrm{c}$ is equal to 2 , and equal to zero in Cox model. ${ }^{14,18)} \mathrm{AIC}$ is used to measure the degree of interaction between complexity of the model and model fit, and ultimately models with the lowest AIC will be selected as the best model.

\section{Results}

Demographic characteristics and extracted data on study variables from medical reports are shown in Table 1. Significant variables in univariate analysis by type of model are presented in Table 2. The significant variables are almost similar in all 5 models $(P<0.20)$. Umbilical arterial catheter was exceptionally not significant in log-normal model. All study variables were eligible to be included in the multivariate regression model.

Log function of neonates survival is shown in Fig. 1, and results of multivariable analysis of Cox model and parametric models are presented in Table $3(P<0.05)$. Fig. 2 shows curve of hazard function of neonates survival in Cox model. Although,

Table 1. Demographics and records of patients included in this study variable

\begin{tabular}{|c|c|c|}
\hline Variable & No. (\%) & $\begin{array}{l}\text { Length of stay (day), } \\
\text { median (IQR) }\end{array}$ \\
\hline Age (day), median (IQR) & \multicolumn{2}{|r|}{$2(1-7)$} \\
\hline Weight (g), median (IQR) & \multicolumn{2}{|c|}{$2,600(1,750-3100)$} \\
\hline \multicolumn{3}{|l|}{ Sex } \\
\hline Male & $360(59.7)$ & $9(4-16)$ \\
\hline Female & $243(40.3)$ & $11(5-13)$ \\
\hline \multicolumn{3}{|l|}{ Type of delivery } \\
\hline Vaginal & $298(49.4)$ & $9(4-17)$ \\
\hline Section & $305(50.6)$ & $10(5-17)$ \\
\hline \multicolumn{3}{|l|}{ Type of feeding } \\
\hline Breastfeeding & $340(56.4)$ & $7(6-18)$ \\
\hline Formula & $263(43.6)$ & $11(3-15)$ \\
\hline \multicolumn{3}{|l|}{ Cause of hospitalization } \\
\hline \multicolumn{3}{|l|}{ Hospital infection } \\
\hline Yes & $327(54.2)$ & $12(6-24)$ \\
\hline No & $276(45.8)$ & $8(4-12)$ \\
\hline \multicolumn{3}{|c|}{ Gastrointestinal disorders } \\
\hline Yes & $132(21.9)$ & $9(5-17)$ \\
\hline No & $471(78.1)$ & $10(5-21)$ \\
\hline \multicolumn{3}{|l|}{ Respiratory disorders } \\
\hline Yes & $440(73.0)$ & $10(5-17)$ \\
\hline No & $163(27.0)$ & $8(6-24)$ \\
\hline
\end{tabular}

Table 1. Continued

\begin{tabular}{|c|c|c|}
\hline Variable & No. (\%) & $\begin{array}{l}\text { Length of stay (day), } \\
\text { median (IQR) }\end{array}$ \\
\hline \multicolumn{3}{|l|}{ Heart disorders } \\
\hline Yes & $129(21.4)$ & $9(4-12)$ \\
\hline No & $474(78.6)$ & $9(5-21)$ \\
\hline \multicolumn{3}{|l|}{ Genetic disorders } \\
\hline Yes & $61(10.1)$ & $11(5-16)$ \\
\hline No & $542(89.9)$ & $9(5-17)$ \\
\hline \multicolumn{3}{|l|}{ Metabolic disorders } \\
\hline Yes & $51(8.5)$ & $12(4-12)$ \\
\hline No & 552 (91.5) & $9(3-18)$ \\
\hline \multicolumn{3}{|l|}{ Acute renal failure } \\
\hline Yes & $42(7.0)$ & $11.5(4-15.2)$ \\
\hline No & $561(93.0)$ & $9(4.5-22.5)$ \\
\hline \multicolumn{3}{|l|}{ Pneumothorax } \\
\hline Yes & $53(8.8)$ & $10(5-17)$ \\
\hline No & $550(91.2)$ & $9(5-30)$ \\
\hline \multicolumn{3}{|l|}{ Intraventricular hemorrhage } \\
\hline Yes & $76(12.6)$ & $12.5(4-16)$ \\
\hline No & $527(87.4)$ & $9(3-25.5)$ \\
\hline \multicolumn{3}{|l|}{ Antibiotic therapy } \\
\hline Yes & 588 (97.5) & $9.5(5-16)$ \\
\hline No & $15(2.5)$ & $5(3-19)$ \\
\hline \multicolumn{3}{|l|}{ Umbilical venous catheterization } \\
\hline Yes & $54(9.0)$ & $5(5-17)$ \\
\hline No & $549(91.0)$ & $10(9-22.7)$ \\
\hline \multicolumn{3}{|l|}{ Umbilical arterial catheterization } \\
\hline Yes & $6(1.0)$ & $5(6-18)$ \\
\hline No & $597(99.0)$ & $10(5-17)$ \\
\hline \multicolumn{3}{|l|}{ Central venous catheterization } \\
\hline Yes & $38(6.3)$ & $3.5(2-35.7)$ \\
\hline No & $565(93.7)$ & $10(5-17)$ \\
\hline \multicolumn{3}{|l|}{ Mechanical ventilation } \\
\hline Yes & $163(27.0)$ & $10(2-13)$ \\
\hline No & $440(73.0)$ & $5(6-18)$ \\
\hline \multicolumn{3}{|l|}{ Oxygen therapy } \\
\hline Yes & $523(86.7)$ & $10(5-17)$ \\
\hline No & $80(13.3)$ & $7(4-12)$ \\
\hline \multicolumn{3}{|l|}{ Surgery during hospitalization } \\
\hline Yes & $83(13.8)$ & $10(6-18)$ \\
\hline No & $520(86.2)$ & $9(4-17)$ \\
\hline \multicolumn{3}{|l|}{ Blood transfusion } \\
\hline Yes & $269(44.6)$ & $14(5-25)$ \\
\hline No & $334(55.4)$ & $7(4-12)$ \\
\hline \multicolumn{3}{|l|}{ Phototherapy } \\
\hline Yes & $257(42.6)$ & $10(5-18)$ \\
\hline No & $346(57.4)$ & $9(5-17)$ \\
\hline \multicolumn{3}{|l|}{ Potomicrography } \\
\hline Yes & $526(87.2)$ & $10(5-18)$ \\
\hline No & 77 (12.8) & $8(5-12)$ \\
\hline \multicolumn{3}{|l|}{ Type of admission } \\
\hline Emergency admission & $163(27.0)$ & $9(5-17)$ \\
\hline Admission from other units & $87(14.4)$ & $11(6-15)$ \\
\hline Referral from other hospitals & $353(58.5)$ & $9(4-18)$ \\
\hline
\end{tabular}


Table 2. Final results of fitted Cox hazard proportional model and parametric models in univariate analysis for NICU length of stay $(P<0.20)$

\begin{tabular}{|c|c|c|c|c|c|c|c|c|c|c|c|c|c|c|c|}
\hline \multirow{2}{*}{ Variable } & \multicolumn{3}{|c|}{ Cox } & \multicolumn{3}{|c|}{ Exponential } & \multicolumn{3}{|c|}{ Weibull } & \multicolumn{3}{|c|}{ Log-normal } & \multicolumn{3}{|c|}{ Log-logistic } \\
\hline & $\mathrm{HR}$ & $P$ value & $\begin{array}{c}95 \% \mathrm{Cl} \\
\text { of } \mathrm{HR}\end{array}$ & HR & $P$ value & $\begin{array}{c}95 \% \mathrm{Cl} \\
\text { of } \mathrm{HR}\end{array}$ & $\mathrm{HR}$ & $P$ value & $\begin{array}{c}95 \% \mathrm{Cl} \\
\text { of } \mathrm{HR}\end{array}$ & TR & $P$ value & $\begin{array}{c}95 \% \mathrm{Cl} \\
\text { of TR }\end{array}$ & TR & $P$ value & $\begin{array}{c}95 \% \mathrm{Cl} \\
\text { of } \mathrm{TR}\end{array}$ \\
\hline Sex & 0.55 & 0.004 & $0.36-0.83$ & 0.53 & 0.002 & $0.35-0.80$ & 0.53 & 0.003 & $0.35-0.81$ & 0.49 & 0.004 & $0.30-0.80$ & 0.48 & 0.004 & $0.29-0.79$ \\
\hline Type of delivery & 1.04 & 0.843 & $0.66-1.40$ & 1.05 & 0.250 & $0.72-1.52$ & 1.05 & 0.815 & $0.72-1.52$ & 1.07 & 0.783 & $0.67-1.69$ & 1.05 & 0.828 & $0.67-1.66$ \\
\hline Weight & 1.00 & 0.008 & $0.99-1.00$ & 0.99 & 0.076 & $0.99-1.00$ & 1.00 & 0.025 & $0.99-1.00$ & 0.99 & 0.006 & $0.99-1.00$ & 0.99 & 0.011 & $0.99-1.00$ \\
\hline Breastfeeding & 0.12 & $<0.001$ & $0.07-0.20$ & 0.12 & $<0.001$ & $0.07-0.20$ & 0.12 & $<0.001$ & $0.07-0.20$ & 0.11 & $<0.001$ & $0.07-0.19$ & 0.10 & $<0.001$ & $0.05-0.17$ \\
\hline Type of admission & 0.68 & 0.257 & $0.35-1.33$ & 0.89 & 0.274 & $0.72-1.10$ & 0.90 & 0.306 & $0.72-1.11$ & 0.96 & 0.738 & $0.74-1.24$ & 0.92 & 0.518 & $0.71-1.19$ \\
\hline Hospital infection & 2.11 & 0.001 & $1.38-3.23$ & 1.70 & 0.012 & $1.12-2.57$ & 1.90 & 0.003 & $1.25-2.91$ & 2.06 & 0.006 & $1.23-3.45$ & 2.22 & 0.004 & $1.29-3.83$ \\
\hline Antibiotic therapy & 0.30 & 0.005 & $0.13-0.69$ & 0.25 & 0.001 & $0.11-0.57$ & 0.27 & 0.002 & $0.12-0.63$ & 0.24 & 0.021 & $0.07-0.24$ & 0.22 & 0.005 & $0.07-0.64$ \\
\hline Phototherapy & 1.78 & 0.003 & $1.22-2.59$ & 1.82 & $<0.001$ & $1.24-2.64$ & 1.77 & 0.003 & $1.22-2.58$ & 2.00 & 0.003 & $1.27-3.16$ & 1.97 & 0.004 & $1.25-3.11$ \\
\hline Genetic disorder & 1.80 & 0.018 & $1.11-2.93$ & 1.69 & 0.033 & $1.04-2.75$ & 1.74 & 0.025 & $1.07-2.83$ & 2.02 & 0.043 & $1.02-3.99$ & 1.96 & 0.041 & $1.03-3.75$ \\
\hline Metabolic disorder & 2.82 & 0.354 & $0.75-2.24$ & 1.18 & 0.552 & $0.68-2.03$ & 1.23 & 0.450 & $0.71-2.13$ & 1.15 & 0.714 & $0.54-2.44$ & 1.22 & 0.572 & $0.61-2.45$ \\
\hline Kidney disorder & 3.27 & $<0.001$ & $2.08-5.15$ & 2.93 & $<0.001$ & $1.87-4.57$ & 3.13 & $<0.001$ & $2.00-4.90$ & 4.97 & $<0.001$ & $2.39-10.3$ & 4.88 & $<0.001$ & $2.48-9.62$ \\
\hline Pneumothorax & 5.29 & $<0.001$ & $3.56-7.87$ & 5.21 & $<0.001$ & $3.52-7.72$ & 5.29 & $<0.001$ & $3.57-7.84$ & 8.08 & $<0.001$ & $4.16-15.7$ & 8.01 & $<0.001$ & $4.43-14.5$ \\
\hline Mechanical ventilation & 14.1 & $<0.001$ & $8.85-22.2$ & 14.6 & $<0.001$ & $9.23-23.1$ & 14.4 & $<0.001$ & $9.09-22.8$ & 15.1 & $<0.001$ & $9.53-24.0$ & 16.6 & $<0.001$ & $10.1-27.4$ \\
\hline Oxygen therapy & 1.29 & 0.357 & $0.75-2.23$ & 1.40 & 0.227 & $0.81-2.41$ & 1.35 & 0.284 & $0.78-2.33$ & 1.44 & 0.288 & $0.74-2.80$ & 1.41 & 0.306 & $0.73-2.74$ \\
\hline Umbilical venous catheterization & 0.19 & $<0.001$ & $0.13-0.28$ & 0.19 & $<0.001$ & $0.13-0.29$ & 5.33 & $<0.001$ & $3.58-7.94$ & 0.11 & $<0.001$ & $0.06-0.21$ & 0.11 & $<0.001$ & $0.06-0.19$ \\
\hline Umbilical arterial catheterization & 0.24 & 0.160 & $0.03-1.76$ & 0.14 & 0.050 & $0.02-0.99$ & 5.27 & 0.102 & $0.72-38.6$ & 0.22 & 0.225 & $0.02-2.53$ & 0.17 & 0.127 & $0.02-1.65$ \\
\hline Central venous catheterization & 0.47 & 0.009 & $0.27-0.83$ & 0.56 & 0.030 & $0.32-0.94$ & 0.50 & 0.011 & $0.29-0.85$ & 0.25 & 0.001 & $0.11-0.56$ & 0.28 & 0.002 & $0.12-0.63$ \\
\hline Photomicrography & 4.35 & 0.012 & $1.38-13.7$ & 3.71 & 0.025 & $1.18-11.7$ & 4.01 & 0.018 & $1.27-12.6$ & 5.25 & 0.004 & $1.70-16.2$ & 5.24 & 0.013 & $1.42-19.3$ \\
\hline Intraventricular hemorrhage & 1.72 & 0.017 & $1.10-2.68$ & 1.59 & 0.039 & $1.02-2.47$ & 1.64 & 0.028 & $1.05-2.55$ & 1.61 & 0.134 & $0.87-3.00$ & 1.68 & 0.079 & $0.94-3.00$ \\
\hline Blood transfusion & 0.27 & $<0.001$ & $0.17-0.45$ & 0.38 & $<0.001$ & $0.24-0.61$ & 0.32 & $<0.001$ & $0.20-0.52$ & 0.24 & $<0.001$ & $0.14-0.44$ & 0.23 & $<0.001$ & $0.12-0.44$ \\
\hline Surgery during hospitalization & 1.21 & 0.497 & $0.70-2.09$ & 1.28 & 0.374 & $0.74-2.21$ & 1.24 & 0.442 & $0.72-2.14$ & 1.48 & 0.254 & $0.75-2.91$ & 1.33 & 0.390 & $0.69-2.58$ \\
\hline Age NICU & 1.04 & 0.014 & $1.01-1.08$ & 1.04 & 0.016 & $1.01-1.07$ & 1.04 & 0.015 & $1.01-1.08$ & 1.04 & 0.012 & $1.01-1.08$ & 1.05 & 0.009 & $1.01-1.09$ \\
\hline
\end{tabular}

$\mathrm{NICU}$, neonatal intensive care unit; $\mathrm{HR}$, hazard ratio; TR, time ratio; $\mathrm{Cl}$, confidence interval.

Boldface indicates a statistically significant difference with $P<0.05$.

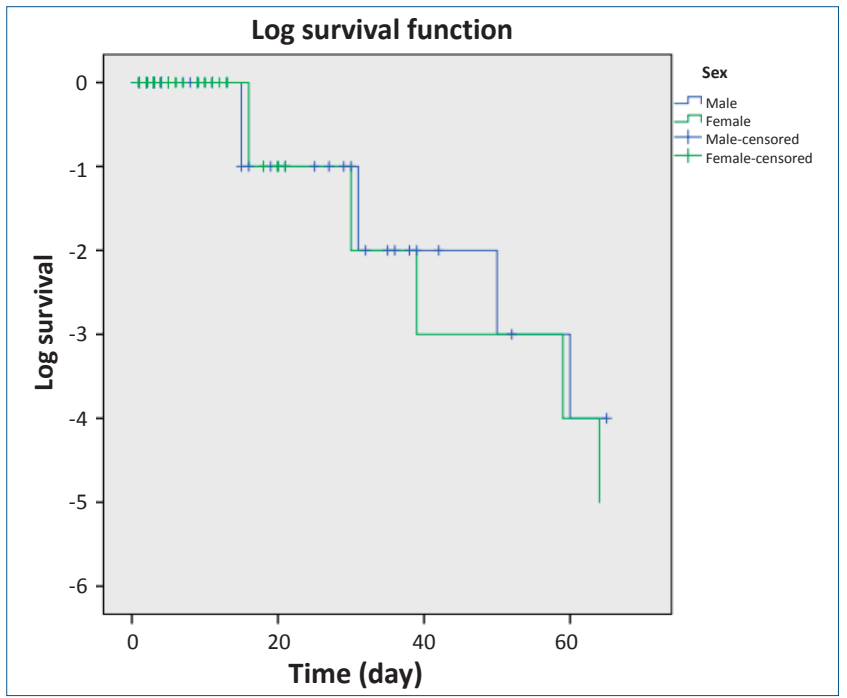

Fig. 1. Log survival function of neonatal care unit length of stay.

results of univariate analysis indicated similar goodness of fit of parametric and semiparametric models, according to AIC (Table 4), parametric model represented a better fitness compared to nonparametric Cox model. Also, among parametric models, exponential model was shown to be the best fitness.

\section{Discussion}

The purpose of this study was to examine factors associated with neonatal LOS in NICU using parametric and semiparametric models, and compare model fitness according to AIC. According to the results of this study, Breastfeeding, phototherapy, acute renal failure, use of mechanical ventilation, and availability of central venous catheter were commonly identified as factors associated with LOS in NICU in all 5 models $(P<0.05)$. In addition, IVH and birth weight presented a proper fit in semiparametric Cox model, and availability of umbilical catheter showed a good fitness in parametric models. Also, gender in the Weibull model, hospital-acquired infection in log-normal and log-logistic models, and availability of umbilical arterial catheter with Weibull and logistic models were shown to be best fitted to the study data.

A population-based cohort study conducted in Australia (2017) revealed that IVH was the most leading cause of neonatal death in NICU (adjusted odds ratio [OR], 9.27; 95\% confidence interval [CI], 6.30-13.64). Also, infant's gender (adjusted OR, 1.47; 95\% CI, 1.10-1.96), and infant's weight $(P<0.001)$ were proved to be associated with infants survival in NICU. ${ }^{19)}$

Another cohort study done in Brazil (2017) proposed that infant's gender $(P=0.038)$, intubation $(P=0.028)$, length of NICU stay $(P=0.012)$, and breastfeeding $(P=0.030)$ were associated with survival of premature infants, with no significant 
Table 3. Final multivariate analysis results of Cox and semiparametric models for neonatal intensive care unit length of stay $(P<0.05)$

\begin{tabular}{|c|c|c|c|c|c|c|c|c|c|c|c|c|c|c|c|}
\hline \multirow{2}{*}{ Variable } & \multicolumn{3}{|c|}{ Cox } & \multicolumn{3}{|c|}{ Exponential } & \multicolumn{3}{|c|}{ Weibull } & \multicolumn{3}{|c|}{ Log-normal } & \multicolumn{3}{|c|}{ Log-logistic } \\
\hline & $H R$ & $P$ value & $\begin{array}{c}95 \% \mathrm{Cl} \\
\text { of } \mathrm{HR}\end{array}$ & HR & $P$ value & $\begin{array}{c}95 \% \mathrm{Cl} \\
\text { of } \mathrm{HR}\end{array}$ & HR & $P$ value & $\begin{array}{c}95 \% \mathrm{Cl} \\
\text { of } \mathrm{HR}\end{array}$ & $\mathrm{TR}$ & $P$ value & $\begin{array}{c}95 \% \mathrm{Cl} \\
\text { of TR }\end{array}$ & TR & $P$ value & $\begin{array}{c}95 \% \mathrm{Cl} \\
\text { of TR }\end{array}$ \\
\hline Sex & \multicolumn{3}{|c|}{ No significance } & \multicolumn{3}{|c|}{ No significance } & 0.66 & 0.05 & $0.42-1.02$ & \multicolumn{3}{|c|}{ No significance } & \multicolumn{3}{|c|}{ No significance } \\
\hline Weight & 1.00 & 0.012 & $0.99-1.00$ & \multicolumn{3}{|c|}{ No significance } & \multicolumn{3}{|c|}{ No significance } & \multicolumn{3}{|c|}{ No significance } & \multicolumn{3}{|c|}{ No significance } \\
\hline Breastfeeding & 0.14 & $<0.001$ & $0.08-0.25$ & 0.15 & $<0.001$ & $0.09-0.25$ & 0.13 & $<0.001$ & $0.07-0.22$ & 0.23 & $<0.001$ & $0.15-0.35$ & 0.24 & $<0.001$ & $0.15-0.38$ \\
\hline Hospital infection & \multicolumn{3}{|c|}{ No significance } & \multicolumn{3}{|c|}{ No significance } & \multicolumn{3}{|c|}{ No significance } & 1.77 & 0.006 & $1.18-2.66$ & 1.57 & 0.035 & $1.03-2.39$ \\
\hline Phototherapy & 1.89 & 0.001 & $1.28-2.78$ & 2.11 & $<0.001$ & $1.40-3.15$ & 2.24 & $<0.001$ & $1.48-3.37$ & 1.64 & 0.014 & $1.11-2.44$ & 1.85 & 0.002 & $1.26-2.73$ \\
\hline Kidney disorder & 2.22 & 0.001 & $1.41-3.51$ & 2.07 & 0.003 & $1.28-3.35$ & 2.10 & 0.003 & $1.29-3.40$ & 2.04 & 0.007 & $1.22-3.41$ & 2.14 & 0.003 & $1.29-3.56$ \\
\hline Mechanical ventilation & 14.9 & $<0.001$ & $9.01-24.5$ & 13.0 & $<0.001$ & $7.71-21.8$ & 15.1 & $<0.001$ & $8.73-26.0$ & 10.6 & $<0.001$ & $6.61-16.9$ & 10.5 & $<0.001$ & $6.41-17.1$ \\
\hline Umbilical venous catheterization & \multicolumn{3}{|c|}{ No significance } & 0.63 & 0.047 & $1.01-2.53$ & 0.61 & 0.035 & $0.38-0.97$ & 0.60 & 0.030 & $0.38-0.95$ & 0.63 & 0.037 & $0.41-0.97$ \\
\hline Umbilical arterial catheterization & \multicolumn{3}{|c|}{ No significance } & \multicolumn{3}{|c|}{ No significance } & 0.10 & 0.036 & $0.01-0.86$ & \multicolumn{3}{|c|}{ No significance } & 0.17 & 0.027 & $0.03-0.81$ \\
\hline Central venous catheterization & 0.45 & 0.008 & $0.25-0.81$ & 0.40 & 0.002 & $0.22-0.71$ & 0.37 & 0.001 & $0.20-0.67$ & 0.53 & 0.028 & $0.30-0.94$ & 0.46 & 0.004 & $0.27-0.79$ \\
\hline Intraventricular hemorrhage & 1.75 & 0.018 & $1.10-2.78$ & \multicolumn{3}{|c|}{ No significance } & \multicolumn{3}{|c|}{ No significance } & \multicolumn{3}{|c|}{ No significance } & \multicolumn{3}{|c|}{ No significance } \\
\hline
\end{tabular}

$\mathrm{HR}$, hazard ratio; $\mathrm{Cl}$, confidence interval; TR, time ratio.

Boldface indicates a statistically significant difference with $P<0.05$.

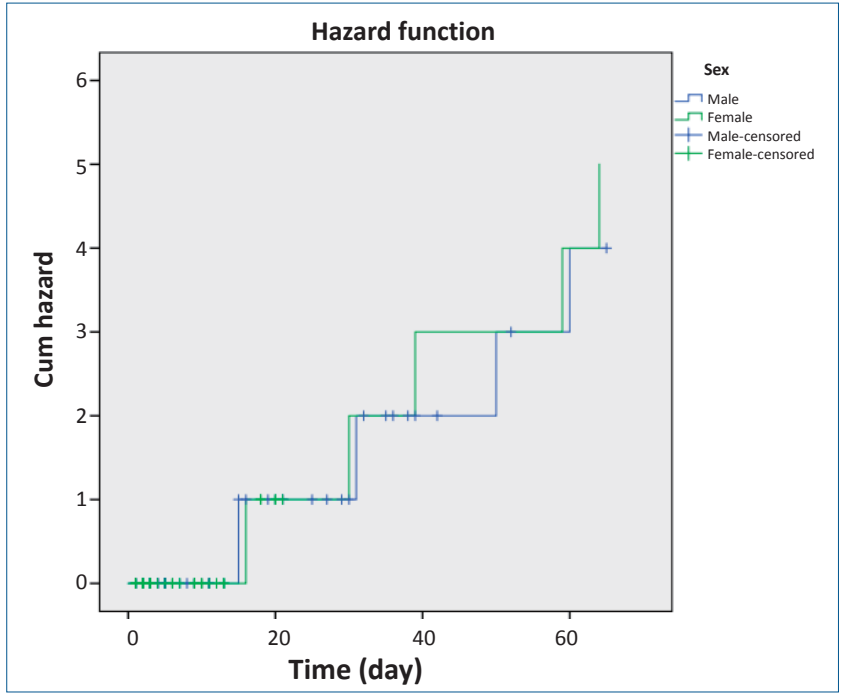

Fig. 2. Cumulative hazard function of neonatal intensive care unit length of stay.

Table 4. Comparison of fitness of models based on AIC

\begin{tabular}{lcc}
\hline Model & Log likelihood & AIC \\
\hline Exponential & -234.54 & 483.08 \\
Weibull & -232.66 & 485.32 \\
Log-normal & -234.45 & 486.90 \\
Log-logistic & -232.17 & 484.34 \\
Cox & -630.57 & 1279.14 \\
\hline
\end{tabular}

AIC, Akaike information criterion.

relationship between infant's weight $(P=0.094)$ and infant survival. ${ }^{20)}$ Besides, another cohort conducted in South Korean (2015) used Cox model and revealed that infant's gender (HR, $1.69 ; 95 \% \mathrm{CI}, 1.10-2.60)$, length of ventilation $(P<0.001)$, IVH $(P<0.001)$, pneumothorax $(P<0.001)$, and respiratory distress syndrome $(P<0.001)$ were associated with LOS in NICU, with no significant association between metabolic disorders such as diabetes with infant survival. ${ }^{21)}$ According to results of a multicenter study conducted in China (2015), IVH was associated with infant survival $(P=0.001)$, and ventilator associated pneumonia was shown to be the most common risk factor for nosocomial infection during NICU stay. ${ }^{22)}$ Cui et al. ${ }^{23)}$ reported that IVH and pulmonary hemorrhage were shown as major risk factors for infant survival in NICU. However, they found no significant relationship between infant survival with hospitalacquired infection $(P=0.92)$ and respiratory distress syndrome $(P=0.42)$.

Stroustrup and Trasande ${ }^{4)}$ and Assandri Dávila et al. ${ }^{24)}$ proposed that respiratory diseases are one of the most medical conditions in hospitalized infants, and a high percentage of these infants need mechanical ventilation and NICU admission. Stroustrup and Trasande ${ }^{4}$ ) also proposed that newborn length of hospital stay significantly increased at birth. They concluded that less use of invasive mechanical ventilation may reduce newborn LOS. Marcin et al. ${ }^{3)}$ also indicated that essential use of mechanical ventilation and intracranial catheters were associated with prolonged NICU stay. Kotloff et al. ${ }^{25)}$ showed that NICU LOS was higher in infants treated with antibiotics during the hospitalization. The results of a cohort study by Freeman et al. $\left.{ }^{26}\right)$ showed that the average LOS was 20 days more in infants with hospital-acquired infection than infants with no infection.

Many studies have been conducted to compare the efficacy of different regression models (parametric, semiparametric and nonparametric), especially for calculating survival rates of different types of cancers, cardiovascular diseases, AIDS, and so on. However, there are a limited number of studies on the survival of newborns in NICU. Unlike our study, Gohari et al. ${ }^{27)}$ (2012) selected the Cox model as the best fitness to estimate the average length of hospital stay, and showed that age and gender were associated with LOS. Kandi Kele et al. ${ }^{28)}$ also evaluated factors associated with NICU LOS using survival analysis based on Cox model as the best model, and reported that prematurity, admission and hospitalization of infants from other hospitals, admission due to gastrointestinal diseases and infections, treatment with mechanical ventilation, use of central venous catheter, and antibiotic treatment were associated with infant survival. 
Ravangard et al. ${ }^{29)}$ showed in their study used Cox model to evaluate factors associated with LOS. They reported that gamma model is an appropriate model with good fit to analyze LOS data, which was consistent with the results of our study. In the present study, parametric models represented better fitness than Cox model.

One of the strength of this study was large sample size due to use of census sampling method. However, the relatively high amount of right censored data was one of the limitations of this study. For an acceptable good fitting of a parametric model, the amount of right censoring should not exceed $40 \%-50 \% .{ }^{30}$ )

Despite the high tendency of researchers to use Cox model in the survival analysis, parametric models can provide better results and predictions in evaluations with minimal censoring compared to Cox model. In the present study, the parametric exponential model represented the best fitness to determine factors associated with neonatal LOS in NICU. Results of this study suggest that breastfeeding and availability of central venous catheter had protective effects against LOS, whereas phototherapy, acute renal failure, and mechanical ventilation increased LOS in NICU. Therefore, identification of factors associated with LOS in NICU can help to establish effective interventions to reduce length of NICU stay among infants. In addition, the findings of this study can help physicians and other healthcare providers to efficiently manage neonatal LOS in NICU. However, parametric models are not undoubtedly the best fitness in survival analysis. Hence, the goodness of fit of various models is variable, and effective analysis of data requires identification of models with the best fitness.

The required data were extracted from hospital information system, and some of the study variables may not be accurately documented. Besides, this study reviewed medical records of one single hospital and results cannot be generalized to other hospitals in Bandar Abbas city.

We suggest that future studies should use various comparative criteria among different models with longer follow-up periods to achieve higher incidence of LOS and reduce the percentage of right censored data.

\section{Conflicts of interest}

No potential conflict of interest relevant to this article was reported.

See the commentary "Survival model application for analy. sis of neonatal length of stay" via https://doi.org/10.3345/cep. 2019.01508 .

\section{References}

1. Manktelow BN, Seaton SE, Field DJ, Draper ES. Population-based estimates of in-unit survival for very preterm infants. Pediatrics 2013;131: e425-32.

2. Seaton SE, Barker L, Draper ES, Abrams KR, Modi N, Manktelow BN, et al. Estimating neonatal length of stay for babies born very preterm. Arch
Dis Child Fetal Neonatal Ed 2019;104:F182-F186.

3. Marcin JP, Slonim AD, Pollack MM, Ruttimann UE. Long-stay patients in the pediatric intensive care unit. Crit Care Med 2001;29:652-7.

4. Stroustrup A, Trasande L. Epidemiological characteristics and resource use in neonates with bronchopulmonary dysplasia: 1993-2006. Pediatrics 2010;126:291-7.

5. Borghans I, Kleefstra SM, Kool RB, Westert GP. Is the length of stay in hospital correlated with patient satisfaction? Int J Qual Health Care 2012; 24:443-51.

6. Jefferies AL; Canadian Paediatric Society, Fetus and Newborn Committee. Going home: facilitating discharge of the preterm infant. Paediatr Child Health 2014;19:31-42.

7. Cox DR. Regression models and life-tables. J R Stat Soc Series B Stat Methodol 1972;34:187-220.

8. Therneau T, Grambsch P. Modeling survival data: extending the Cox model. New York: Springer Science \& Business Media; 2000.

9. Kargarian Marvasti S, Abolghasemi J, Heydari I, Rimaz SH. Effective factors in the time of development of neuropathy in type II diabetic patients. Iran J Epidemiol 2017;13:80-9.

10. Stata survival analysis and epidemiological tables: reference manual. College Station, TX; Stata Corporation; 2003.

11. Collett D. Modelling survival data in medical research. London: Chapman and Hall; 1986.

12. Cox D, Oakes D. Analysis of survival data. London: Chapman and Hall; 1986.

13. Klein JP, Moeschberger ML. Survival analysis: techniques for censored and truncated data. New York: Springer-Verlag; 1997.

14. Hougaard P. Analysis of multivariate survival data. 2nd ed. New York: Springer-Verlag; 2000.

15. Saneie H. Analysis of survival data. Tehran: Andishmand; 2001.

16. Akaike H. A new look at the statistical model identification. IEEE Trans Autom Control 1974:19:716-23.

17. Kargarian-Marvasti S, Rimaz S, Abolghasemi J, Heydari I. Comparing of Cox model and parametric models in analysis of effective factors on event time of neuropathy in patients with type 2 diabetes. J Res Med Sci 2017;22:115.

18. Klein JP, Moeschberger ML. Survival analysis: techniques for censored and truncated data. 2nd ed. New York: Springer; 2006.

19. Schindler T, Koller-Smith L, Lui K, Bajuk B, Bolisetty S; New South Wales and Australian Capital Territory Neonatal Intensive Care Units' Data Collection. Causes of death in very preterm infants cared for in neonatal intensive care units: a population-based retrospective cohort study. BMC Pediatr 2017;17:59.

20. Cortines AA, Costa LR. Associated factors and persistence of palatal groove in preterm infants: a cohort study. BMC Pediatr 2016;16:143.

21. Lim JW, Chung SH, Kang DR, Kim CR. Risk factors for cause-specific mortality of very-low-birth-weight infants in the Korean Neonatal Network. J Korean Med Sci 2015;30 Suppl 1(Suppl 1):S35-44.

22. Lin HJ, Du LZ, Ma XL, Shi LP, Pan JH, Tong XM, et al. Mortality and morbidity of extremely low birth weight infants in the mainland of China: a multi-center study. Chin Med J (Engl) 2015;128:2743-50.

23. Cui YZ, Zhang QS, He HY, Chen C. Analysis of survival and prognostic factors in extremely preterm infants. Zhongguo Dang Dai Er Ke Za Zhi 2014;16:596-600.

24. Assandri Dávila E, Ferreira García MI, Bello Pedrosa O, de Leonardis Capelo D. Neonatal hospitalization through a hospital emergency service in Uruguay. An Pediatr (Barc) 2005;63:413-7.

25. Kotloff KL, Blackmon LR, Tenney JH, Rennels MB, Morris JG Jr. Nosocomial sepsis in the neonatal intensive care unit. South Med J 1989; 82:699-704.

26. Freeman J, Epstein MF, Smith NE, Platt R, Sidebottom DG, Goldmann DA. Extra hospital stay and antibiotic usage with nosocomial coagulasenegative staphylococcal bacteremia in two neonatal intensive care unit populations. Am J Dis Child 1990;144:324-9.

27. Gohari M, Vahabi N, Moghadamifard Z. Semi-parametric Cox regression for factors affecting hospitalization length. Daneshvar Med J 2012;19:2330 . 
28. Kandi Kele M, Kadivar M, Zeraati H, Ahmadnezhad E, Holakoui Naini $\mathrm{K}$. Length of stay in NICU admitted infants and its effective factors at children's hospital medical center using survival analysis. Iran J Epidemiol 2014;10:25-32.

29. Ravangard R, Arab M, Rashidian A, Akbarisari A, Zare A, Zeraati H.
Comparison of the results of Cox proportional hazards model and parametric models in the study of length of stay in a tertiary teaching hospital in Tehran, Iran. Acta Med Iran 2011;49:650-8.

30. Nardi A, Schemper M. Comparing Cox and parametric models in clinical studies. Stat Med 2003;22:3597-610. 